\title{
Wnt3a protects SH-SY5Y cells against 6-hydroxydopamine toxicity by restoration of mitochondria function
}

\author{
Lei Wei ${ }^{1,2^{*}}$, Li Ding ${ }^{3}$, Ming-shu Mo ${ }^{2}$, Ming Lei ${ }^{2}$, Limin Zhang ${ }^{2}$, Kang Chen ${ }^{5}$ and Pingyi $\mathrm{Xu}^{2,4^{*}}$
}

\begin{abstract}
Background: Wnt/ $\beta$-catenin signal has been reported to exert cytoprotective effects in cellular models of several diseases, including Parkinson's disease (PD). This study aimed to investigate the neuroprotective effects of actived Wnt/ß-catenin signal by Wnt3a on SH-SY5Y cells treated with 6-hydroxydopamine (6-OHDA).

Methods: Wnt3a-conditioned medium (Wnt3a-CM) was used to intervene dopaminegic SH-SY5Y cells treated with 6-OHDA. Cell toxicity was determined by cell viability and lactate dehydrogenase leakage (LDH) assay. The mitochondria function was measured by the mitochondrial membrane potential, while oxidative stress was monitored with intracellular reactive oxygen species (ROS). Western blot analysis was used to detect the expression of GSK3 $\beta$, $\beta$-catenin as well as Akt.

Results: Our results showed that $100 \mu \mathrm{M}$ 6-OHDA treated for $24 \mathrm{~h}$ significantly decreased cell viability and mitochondrial transmembrane potential, reduced the level of $\beta$-catenin and p-Akt, increased LDH leakage, ROS production and the ratio of p-GSK3 $\beta$ (Tyr216) to p-GSK3 $\beta$ (Ser9). However, Wnt3a-conditioned medium reversing SH-SY5Y cells against 6-OHDA-induced neurotoxicity by reversing these changes.

Conclusions: Activating of Wnt/ $\beta$-catenin pathway by Wnt3a-CM attenuated 6-OHDA-induced neurotoxicity significantly, which related to the inhibition of oxidative stress and maintenance of normal mitochondrial function.
\end{abstract}

Keywords: Wnt3a, 6-OHDA, Mitochondria function, Parkinson's disease

\section{Background}

Parkinson's disease (PD), characterized by loss of dopaminergic neurons in substantia nigra, is the second most common neurodegenerative diseases in elderly people. Studies have shown that several mechanisms are involved in pathogenesis of PD including oxidative stress, mitochondrial dysfunction and elevated brain iron levels [1-3]. Although much research has helped to elucidate the pathogenesis of $\mathrm{PD}$, the precise etiology and pathogenesis of the disease still remain unknown. Moreover, Current treatments for PD predominantly rely on pharmacotherapy to improve the symptoms of movement disorder, but little efficacy in preventing disease progression. Therefore neuroprotective therapy may play a key role in the therapeutic strategy of PD.

\footnotetext{
* Correspondence: weilei068@163.com; pingyixu@sina.com

'Department of Neurology, The Third Affiliated Hospital of Sun Yat-sen University, Guangzhou 510630, China

${ }^{2}$ Department of Neurology, The First Affiliated Hospital of Sun Yat-sen University, Guangzhou 510080, China

Full list of author information is available at the end of the article
}

Wnt signaling pathway is an autocrine-paracrine signal transduction pathway which has been demonstrated to participate in embryonic development, cell differentiation and ontogenesis [4-7]. A main Wnt signaling pathway branch is the wnt $/ \beta$-catenin pathway, which initiates with Wnt proteins binding to Frizzled receptors and activates Dishevelled. Activation of Dishevelled results in inhibition of glycogen synthase kinase- $3 \beta$ (GSK3 $\beta$ ), which in turn causes stabilization of $\beta$-catenin. Stabilized $\beta$-catenin accumulates and is taken into the nucleus where it regulates expression of numerous genes [8]. Extensive research has confirmed the vital role of Wnt signaling in midbrain dopaminergic neuronal development $[9,10]$. For example, Wnt1 and Wnt3a, which exert effects by Wnt/ $\beta$-catenin pathway, are key regulators in the development of dopaminergic neurons [9].

The cellular protective effects of Wnt/ $\beta$-catenin pathway have been demonstrated in animal and cellular 
models of Alzheimer's disease, retinal degeneration, cerebral ischemia as well as PD [11-14]. Our previous study hasdemonstrated that $\mathrm{Wnt} / \beta$-catenin signal is inhibited in SH-SY5Y cells treated with 6-OHDA, a cellular model of PD, while activation of $\mathrm{Wnt} / \beta$-catenin signal by exogenous Wnt1 could protect cells by restoring mitochondria and endoplasmic reticulum function [15]. However, the precise mechanism for the pathogenesis of the disease remains unknown. In this study, we report that Wnt3a-conditioned medium (Wnt3a-CM) protected cells from 6-OHDA neurotoxicity by a mechanism that involved maintenance of normal mitochondrial.

\section{Methods}

\section{Cell culture}

Human neuroblastoma SH-SY5Y cells were obtained from American Type Culture Collection (ATCC, Manassas, VA, U.S.A.), maintained in DMEM with high glucose (Invitrogen, USA) supplemented with $10 \%$ fetal bovine serum (FBS, Invitrogen), and cultured in a humidified incubator with $5 \% \mathrm{CO}_{2}$ at $37{ }^{\circ} \mathrm{C}$. Cells with $20-30$ passages were used. For experiments, cells were seeded at a density of $1 \times 10^{5} / \mathrm{cm}^{2}$ in the plastic flasks or plates. Conditioned media containing Wnt3a (Wnt3a-CM) were prepared from mouse L cells (ATCC) stably expressing Wnt3a. Control conditioned media were obtained from parental L cells (Ctrl-CM). Different proportions of Ctrl$\mathrm{CM}$ or Wnt3a-CM were performed according to corresponding experiments.

\section{Cell viability assay}

SH-SY5Y cells were seeded in a 96-well plate at a density of $1 \times 10^{3}$ cells per well. After attachment, cells were treated with $100 \mu \mathrm{M}$ 6-OHDA, Ctrl-CM (10-80\%) or Wnt3a-CM (10-80 \%) for $24 \mathrm{~h}$. After treatment, cells were incubated with $0.5 \mathrm{mg} / \mathrm{mL}$ MTT (Sigma-Aldrich, USA) for $4 \mathrm{~h}$ at $37{ }^{\circ} \mathrm{C}$ [16]. Following aspiration of the MTT solution, the same volume of DMSO was added into each well to dissolve the purple formazan crystals. Absorbance was read in a microtiter plate reader at $490 \mathrm{~nm}$. Cell viability was expressed as a percentage of the absorbance from control cells. The toxic effects of 6OHDA to SH-SY5Y cells were also detected by measuring the leakage of the cytosolic enzyme LDH to the culture medium using a colorimetric LDH assay kit (KeyGen, China) according to the manufacturer's instructions [17]. Briefly, after $100 \mu \mathrm{M}$ 6-OHDA added, $20 \mu \mathrm{l}$ of cell medium were added into basic solution to measure extracellular LDH activity, which could catalyze the conversion of lactate to pyruvate, which then reacted with 2,4-dinitrophenylhydrazine to give the brownish red color. The absorbance was measured at a wavelength of $440 \mathrm{~nm}$ by colorimetric assay, and the LDH leakage was expressed as the percentage versus control cells.

\section{Measurement of mitochondrial transmembrane potential (MMP) and intracellular ROS production}

Changes in the mitochondrial membrane potential with various treatments in SH-SY5Y cells were measured by rhodamine-123 or DCFH-DA using a fluorescence spectrophotometer [18]. Briefly, cells were treated with 6OHDA, Ctrl-CM and Wnt3a-CM for $24 \mathrm{~h}$ and then incubated with rhodamine-123 (Sigma-Aldrich, USA) or DCFH-DA (Sigma-Aldrich, USA) in a final concentration of 10 or $25 \mu \mathrm{mol} / \mathrm{L}$ respectively for $30 \mathrm{~min}$ at $37^{\circ} \mathrm{C}$. After washing twice with HEPES buffer saline (Invitrogen, USA), fluorescence was recorded at $488 \mathrm{~nm}$ excitation and $523 \mathrm{~nm}$ emission wave-lengths. Each field of cells was photographed using a fluorescence microscopy.

\section{Western blot analysis}

The immunoblotting was performed in accordance with a standard procedure $[16,19]$. The following primary antibodies were used: rabbit anti- $\beta$-catenin (1:1000 dilution, Abcam, Cambridge, UK), rabbit anti-p-GSK3 $\beta$ (Ser9) (1:1000 dilution, CST, USA), rabbit anti-p-GSK3 $\beta$

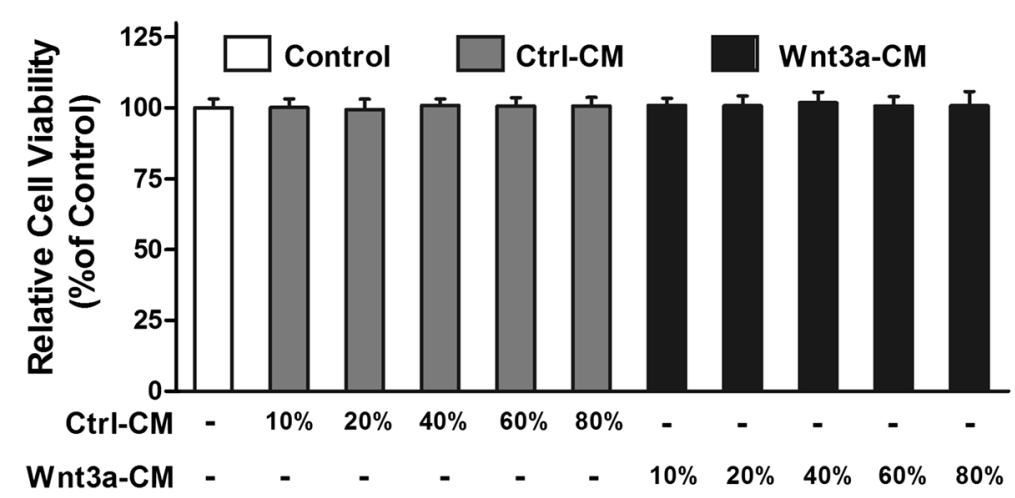

Fig. 1 Treatment with Wnt3a-CM or Ctrl-CM didn't change SH-SY5Y cell viability. SH-SY5Y cells were treated with different proportion of Ctrl-CM or Wnt3a-CM, cell viability was measured by MTT assay. Data were presented as mean \pm SD from four independent experiments 


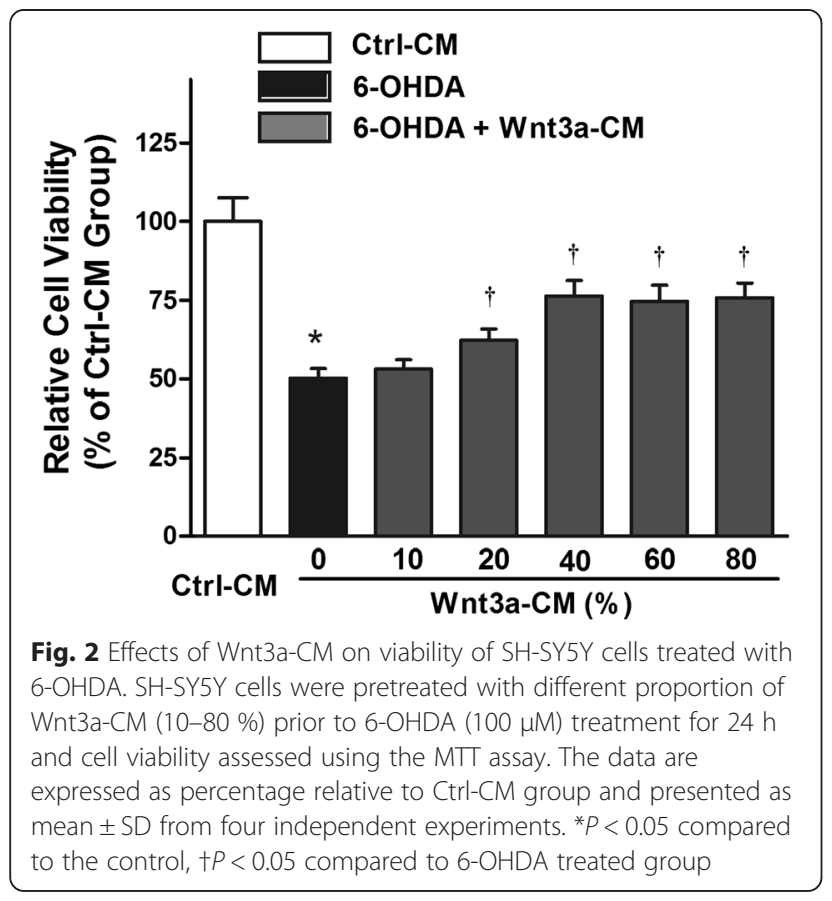

(Tyr216) (1:1000 dilution, CST, USA), rabbit anti-p-Akt (Ser473) (1:1000 dilution, Millipore, USA), mouse anti$\beta$-actin (1:1000 dilution, Millipore, USA). Proteins were detected with the SuperSignal ${ }^{\circ}$ West Pico Chemiluminescent Substrate (Thermo Fisher Scientific Inc., IL, USA) and membranes were exposed to X-ray films (Fujifilm Corporation, Japan), which were scanned and analyzed by using the Quantity One v4.62 for Windows software (Biorad, CA, USA).

\section{Statistical analysis}

Results were presented as mean $\pm \mathrm{SD}$. One-way analysis of variance (ANOVA) followed by Student-Newman-Keuls test was used to compare differences between means in more than two groups. The level of significance was set at $P<0.05$. All the statistical analyses were performed with SPSS 12.0 for windows (SPSS Inc., Chicago, IL, USA).

\section{Results}

\section{Wnt3a-CM attenuated 6-OHDA-induced cell injury}

Our previous studies have confirmed that treatment with 6-OHDA for $24 \mathrm{~h}$ caused a concentration-dependent reduction in cell viability and a concentration-dependent increase in LDH release in dopaminergic SH-SY5Y cells [15]. According to our previous results, a $100 \mu \mathrm{M} 6$ OHDA was chosen for the following experiments.

We then tested the effect of Wnt3a-CM on SH-SY5Y cells, and found that treatment with Wnt3a-CM or Ctrl$\mathrm{CM}$ at proportion of $10-80 \%$ didn't obviously change the cell viability (Fig. 1). Thus, Ctrl-CM at a proportion of $40 \%$ was used as control and we investigated whether
Wnt3a-CM could attenuate the toxic effect of 6-OHDA on SH-SY5Y cells. Wnt3a-CM was added to the cultures at different proportion $20 \mathrm{~min}$ prior to 6-OHDA. Cells pre-treated with Wnt3a-CM were partially protected against 6-OHDA toxicity. Treatment with $100 \mu \mathrm{M}$ 6OHDA for $24 \mathrm{~h}$ decreased the cell viability to $~ 50 \%$ compared with Ctrl-CM group. However, when cells were pre-treated with Wnt3a-CM the reduction of cell viability was ameliorated. Specifically, the level of cell viability increased to $62.16 \pm 3.71 \%$ of the control value when $20 \%$ of Wnt3a-CM was used and that was up to $76.35 \pm 5.00 \%$ when $40 \%$ of Wnt3a-CM was added. Then the cell viability of higher proportion of Wnt3aCM (60 and $80 \%$ ) was reduced to $74.64 \pm 5.21$ and $75.79 \pm 4.71$ respectively (Fig. 2). Similarly, pretreatment of 20, 40, 60 and $80 \%$ Wnt3a-CM could significantly inhibit LDH release induced by 6-OHDA (Fig. 3).

\section{Wnt3a-CM antagonized 6-OHDA-induced MMP and ROS production}

It is generally accepted that the 6-OHDA-induced neuronal apoptosis is mediated by the mitochondrial dysfunction. Markers of mitochondria function, such as mitochondrial membrane potential are often used to monitor the cell apoptosis. In the experiment, there was a significant reduction of MMP in 6-OHDA-treated SH-SY5Y cells. However, a partial restoration of MMP was observed in the cells treated with Wnt3a-CM at a proportion of 40 \% (Fig. 4a and 4c). In consideration of ROS

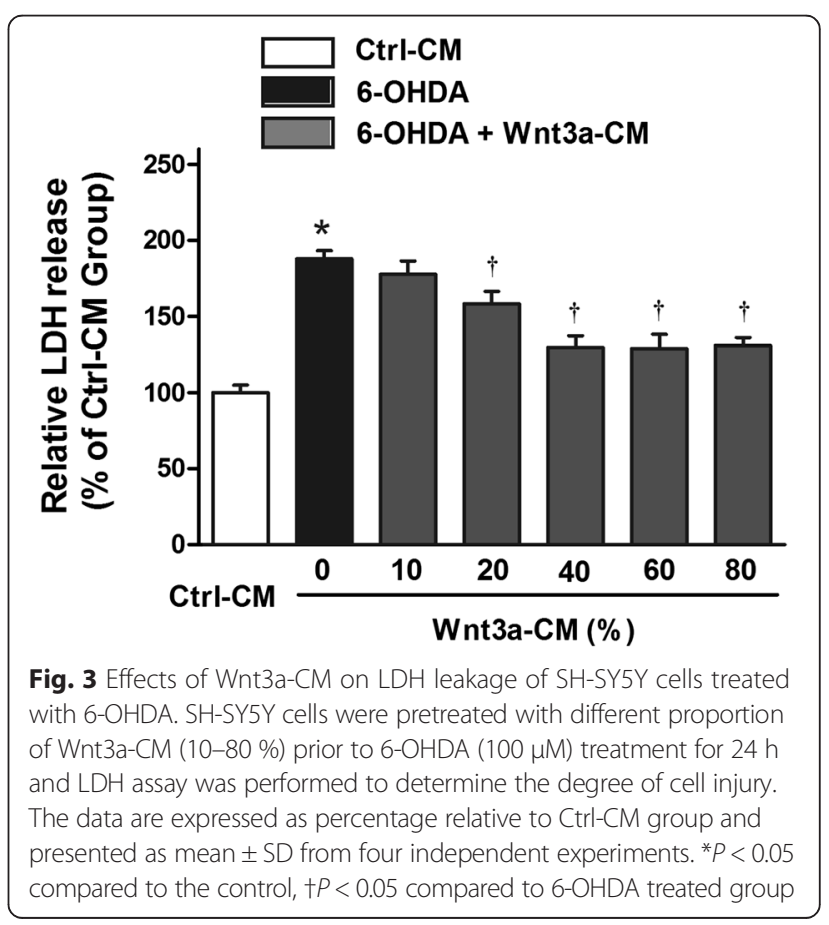




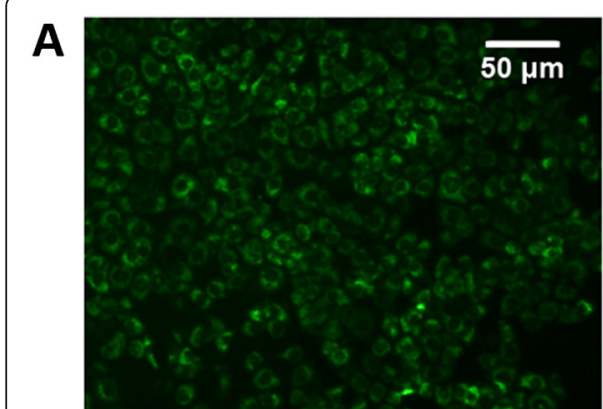

Ctrl-CM

B

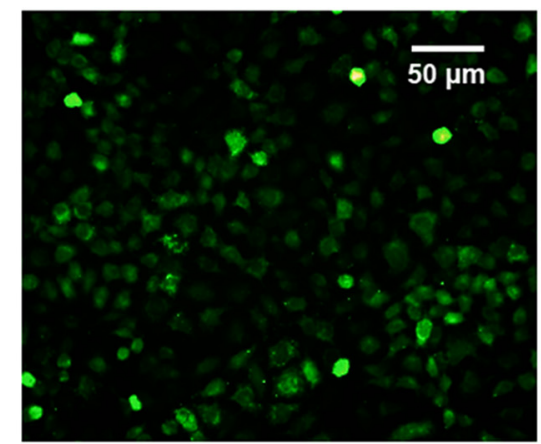

Ctrl-CM

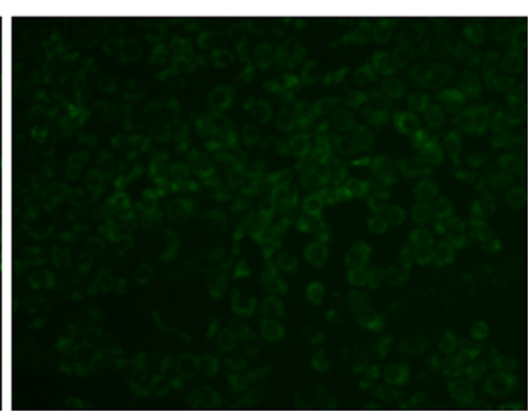

Ctrl-CM + 6-OHDA

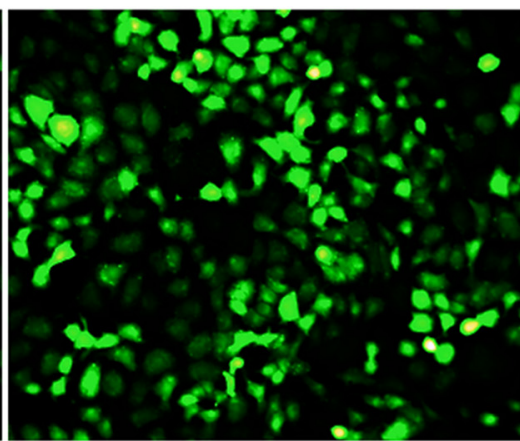

Ctrl-CM + 6-OHDA

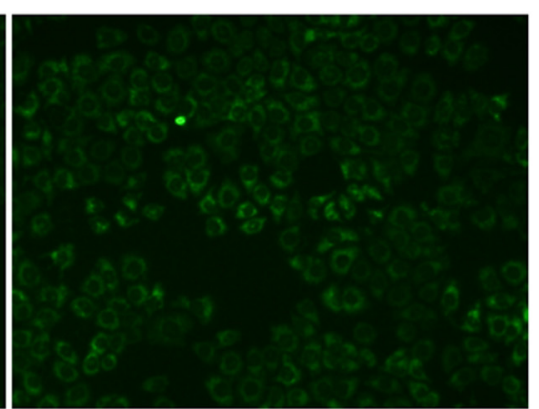

Wnt3a-CM + 6-OHDA

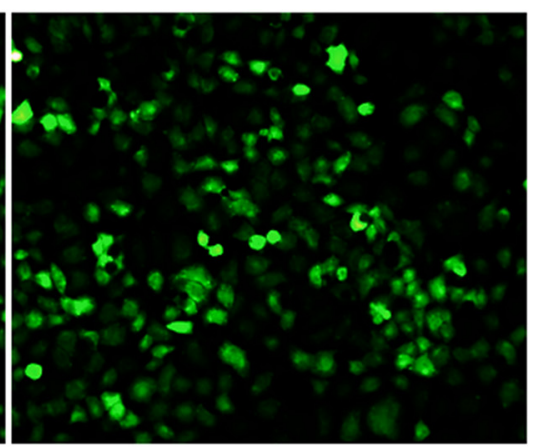

Wnt3a-CM + 6-OHDA

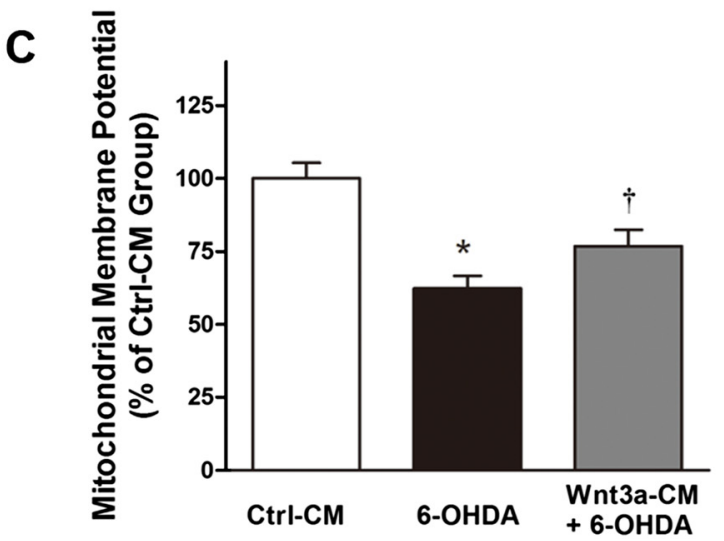

D

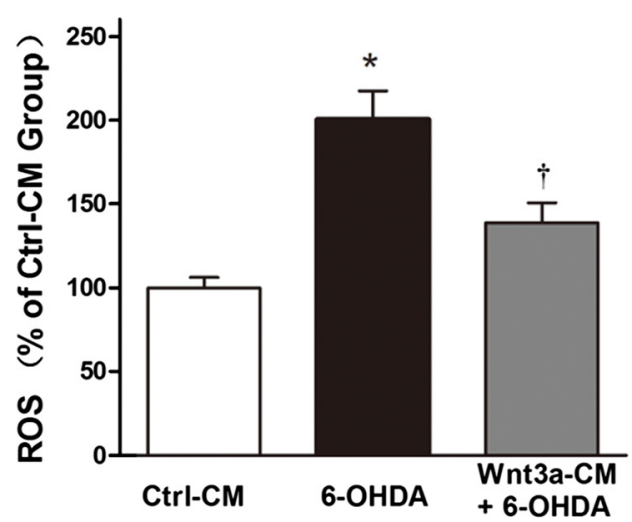

Fig. 4 Mitochondrial membrane potential (MMP) AND intracellular ROS production. SH-SY5Y cells were treated with Ctrl-CM, Ctrl-CM + 6-OHDA $(100 \mu \mathrm{M})$ or Wnt3a-CM (40 \%) 20 min prior to 6-OHDA for 24 h, MMP (a) and intracellular ROS (b) were photographed by a fluorescence microscopy. Results of MMP (c) and intracellular ROS (d) are detected by a fluorescence spectrophotometer and expressed as relative fluorescent intensity. Data were presented as mean \pm SD from four independent experiments. ${ }^{*} P<0.05$ compared to $\mathrm{Ctrl}-\mathrm{CM}$ group, $+P<0.05$ compared to Ctrl-CM $+6-\mathrm{OHDA}$ group

elevation believed to initiate a neurotoxic cascade induced by 6-OHDA [20], we further examined if Wnt3a-CM inhibit 6-OHDA-induced cell apoptosis by suppressing ROS production. As shown in Fig. 4b and d, 6-OHDA treatment alone for $24 \mathrm{~h}$ induced about 2 -fold increase in ROS level compared to the control group, whereas pretreatment with $40 \%$ Wnt3a-CM exhibited an inhibitive effect of ROS production from cells.
Wnt3a-CM activated Wnt/ $\beta$-catenin pathway

To verify the activation effect of Wnt3a-CM on Wnt/ $\mathrm{W}$ catenin pathway, western blot was used to detect the expression of p-GSK3 $\beta$ (Ser9), p-GSK3 $\beta$ (Tyr216) and $\beta$-catenin in SH-SY5Y cells. Because the activity of GSK3 $\beta$ is regulated negatively by the phosphorylation of serine 9 (Ser9) and positively by the phosphorylation of tyrosine 216 (Tyr216) [21], the ratio of p-GSK3 $\beta$ (Tyr216) 
to $\mathrm{p}-\mathrm{GSK} 3 \beta$ (Ser9) can be used to monitor the activity of GSK3 $\beta$. We found that treatment of $100 \mu \mathrm{M}$ 6-OHDA for $24 \mathrm{~h}$ increase the ratio of $\mathrm{p}-\mathrm{GSK} 3 \beta$ (Tyr216) to $\mathrm{p}$-GSK3 $\beta$ (Ser9), and decrease $\beta$-catenin level. However, pretreatment with Wnt3a-CM reverse these changes induced by 6-OHDA treatment (Fig. 5a, b and c).
Wnt3a-CM reversed 6-OHDA-induced Akt down-regulation

Investigation has documented that Wnt signal rely upon PI3K/Akt activation to support the cell survival [22]. Here we detected the level of p-Akt (Ser473) protein, an active form of Akt, in SH-SY5Y cells treated with
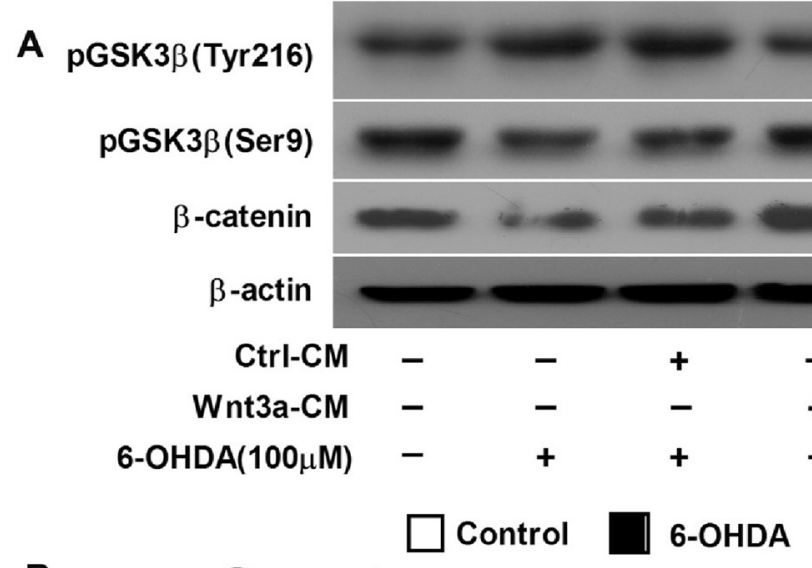

46KD

B

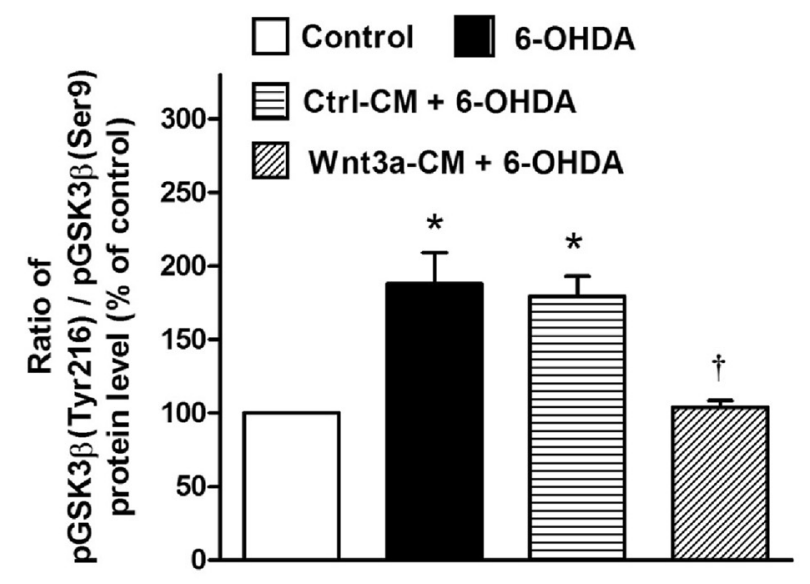

c

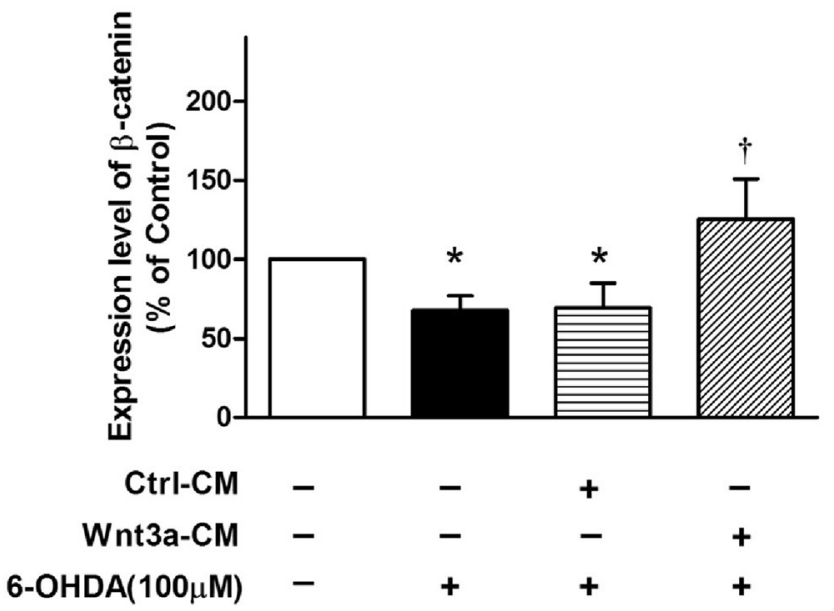

Fig. 5 Change of related signal proteins in the cytoprotective effect of Wnt3a-CM in Sh-SY5Y treated with 6-OHDA. SH-SY5Y cells were treated with vehicle, 6-OHDA (100 $\mu \mathrm{M})$, Ctrl-CM, or Wnt3a-CM (40\%) 20 min prior to 6-OHDA for $24 \mathrm{~h}$, the protein levels of 2 phosphorylation forms of GSK3 $\beta$ and $\beta$-catenin (a) were detected by Western blot with $\beta$-actin as internal control. The band intensities were measured by Quantity One software and normalized to the expression of $\beta$-actin in SHSY5Y cells. The ratio of p-GSK3 $\beta$ (Tyr216) to p-GSK3 $\beta$ (Ser9) (b) and the relative levels of $\beta$-catenin (c) were expressed in histogram. Data were presented as mean \pm SD of 3 experiments. ${ }^{*} P<0.05$ compared to the control, $+P<0.05$ compared to Ctrl-CM + 6-OHDA group 
6-OHDA or/and Wnt3a-CM. We found that the pAkt protein level in 6-OHDA treated group were decreased to $\sim 54 \%$ compared with control group, while that in cells pretreatment of Wnt3a-CM was $~ 88 \%$ (Fig. 6), which suggested that treatment of Wnt3a might reverse the down-regulation of PI3K/Akt pathway by 6OHDA treatment.

\section{Discussion}

This study investigated the protective effects of Wnt3aconditioned medium on a cellular model of PD and showed that Wnt/ $\beta$-catenin pathway was inhibited after treatment of $100 \mu \mathrm{M}$ 6-OHDA for $24 \mathrm{~h}$, evidenced by the decreased $\beta$-catenin level and increased GSK3 $\beta$ activity. Moreover, activating Wnt/ $\beta$-catenin pathway by Wnt3a-CM was found to attenuate 6-OHDA-induced neurotoxicity in SH-SY5Y cells through restoration of mitochondria transmembrane potential and reducing ROS production, indicating the $\mathrm{Wnt} / \beta$-catenin pathway related to the maintenance of mitochondrial function.

SH-SY5Y cell line chosen in this study was considered for its expression of tyrosine hydroxylase $(\mathrm{TH})$ simulating to dopaminergic neurons [23]. As an endogenous oxidative metabolite of dopamine, 6-OHDA could inhibit the mitochondrial respiratory chain through inhibiting Complex I, uncoupling oxidative phosphorylation and collapsing mitochondrial membrane [24-26]. It is thought that 6-OHDA induces toxicity that mimics the neuropathological and biochemical characteristics of PD in SHSY5Y cells [27].

Wnt3a is one of the Wnt ligands that activate the canonical Wnt pathway [28]. Because the purified Wnt3a is unstable, the Wnt3a conditioned medium is commonly used for the activation of the canonical Wnt pathway in in vitro experiments [29]. Recently, L'Episcopo et al. found the $\beta$-catenin protein acts as a pro-survival factor for mesencephalic $\mathrm{TH}^{+}$neurons [14]. Meanwhile, Dickkopf-1 (DKK1), a negative regulator of the Wnt/ $\beta$-catenin signaling pathway, was found to promote apoptosis of SH-SY5Y cells [30]. Dun Y and colleagues also found that induction of DKK1 contributes to the $\mathrm{MPP}^{+}$-induced neurotoxicity in PC12 cells via inhibition of the canonical Wnt pathway, and inhibition of DKK1 which could rescue the Wnt pathway might

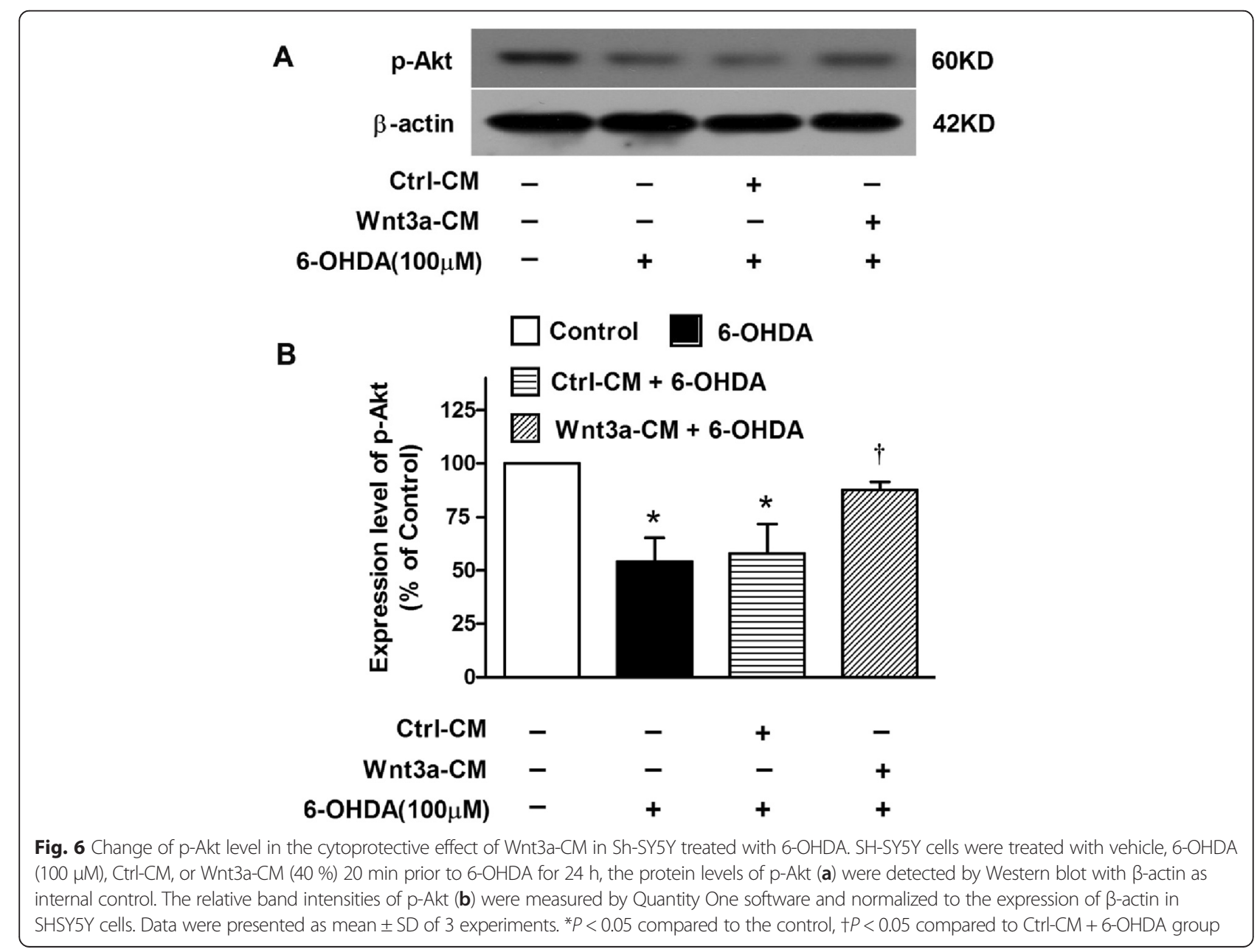


be neuroprotective in PD [31]. Our present study also confirmed that Wnt3a-CM increase the $\beta$-catenin protein level, which might contribute to the protective effect on cells. Moreover, our previous study uncovered that downregulation of GSK3 $\beta$, also a central component of the Wnt/ $\beta$-catenin pathway, attenuate 6-OHDA-induced neuronal death and apoptosis [25]. The inhibition of GSK3 $\beta$ was reported to be linked with the attenuation of oxidative stress [32]. Data in this study confirmed that Wnt3a-CM inhibited the activity of GSK3 $\beta$ by increasing the phosphorylation at site Ser9 and decreasing the phosphorylation at site Tyr216.

Due to the mitochondrial dysfunction was considered a key factor in PD onset, we also measured MMP and ROS production from the SH-SY5Y cells in vitro. Mitochondria is the major site of ROS production and also prime target of oxidative molecular damage, the consequent formation of ROS further damages the mitochondrial membrane and such damages are implicated as key events in the pathogenic cascades leading to apoptosis [24, 33]. Shin SY and colleagues reported that stimulation of Wnt signaling by Wnt3a-CM inhibits $\mathrm{H}_{2} \mathrm{O}_{2}$-induced mitochondrial cytochrome $\mathrm{C}$ release and DNA fragmentation L1210 cells [34]. In this experiment, we found that Wnt3a$\mathrm{CM}$ eliminated ROS production, stabilized mitochondrial transmembrane potential in SH-SY5Y cells.

PI3K and Akt are central to the regulation of cell growth and survival throughout the body [35, 36]. Akt, which is also known as protein kinase B (PKB), is a key molecule in growth factor signaling pathways mediating neuronal survival in both development and disease in multiple paradigms, including resistance against oxidative insults in the brain and protection of mitochondria function [37, 38]. Here our data showed that Wnt3a-CM reverse the down-regulation of p-Akt (Ser473) which is the active form of Akt caused by 6-OHDA treatment, clearly suggesting the mediation of the PI3K/ Akt pathway in the protective effect of Wnt3a-CM on 6-OHDA-induced cell injury.

In conclusion, our data showed that activating of Wnt/ $\beta$ catenin pathway by Wnt3a attenuated 6-OHDA-induced neurotoxicity, which involved in the mechanism about the inhibition of oxidative stress relate to the mitochondrial functional maintenance. These result may provide a new potential therapeutic target for Parkinson's diseases.

\section{Competing interests}

The authors declare that they have no competing interest and have approved the final article.

\section{Authors' contributions}

$L W, L D, M S M, M L$ and LMZ performed the research; LW, KC and PYX participated in the design of the study and performed the statistical analysis. LW prepared the manuscript. All authors read and approved the final manuscript.

\section{Acknowledgements}

This work was supported by Nature Science Foundation of China (81401058, 81401645,81271428 and 81471292), a grant from the State Key Development Program for Basic Research of China (2011CB510000), a grant from Medical Scientific Research Foundation of Guangdong Province (B2014139) and a grant supported by assisting research project of science and technology for Xinjiang (201591160).

\section{Author details}

${ }^{1}$ Department of Neurology, The Third Affiliated Hospital of Sun Yat-sen University, Guangzhou 510630, China. ${ }^{2}$ Department of Neurology, The First Affiliated Hospital of Sun Yat-sen University, Guangzhou 510080, China. ${ }^{3}$ Department of pathology, The First Affiliated Hospital of Sun Yat-sen University, Guangzhou 510080, China. ${ }^{4}$ Department of Neurology, The First Affiliated Hospital of Guangzhou Medical University, Guangzhou 510120, China. ${ }^{5}$ Division of Clinical Laboratory, Zhongshan Hospital of Sun Yat-sen University, Zhongshan 528403, China.

Received: 18 April 2015 Accepted: 9 June 2015

Published online: 16 June 2015

\section{References}

1. Andersen JK. Oxidative stress in neurodegeneration: cause or consequence? Nat Med. 2004;10(Suppl):S18-25. doi:10.1038/nrn1434.

2. Schapira AH, Gegg M. Mitochondrial contribution to Parkinson's disease pathogenesis. Parkinsons Dis. 2011;2011:159160. doi:10.4061/2011/159160.

3. Dexter DT, Carayon A, Javoy-Agid F, Agid Y, Wells FR, Daniel SE, et al. Alterations in the levels of iron, ferritin and other trace metals in Parkinson's disease and other neurodegenerative diseases affecting the basal ganglia. Brain. 1991;114(Pt 4):1953-75.

4. Li F, Chong ZZ, Maiese K. Winding through the WNT pathway during cellular development and demise. Histol Histopathol. 2006;21(1):103-24.

5. Yamaguchi TP. Heads or tails: Wnts and anterior-posterior patterning. Curr Biol. 2001;11(17):R713-24.

6. Mazemondet O, Hubner R, Frahm J, Koczan D, Bader BM, Weiss DG, et al. Quantitative and kinetic profile of Wnt/beta-catenin signaling components during human neural progenitor cell differentiation. Cell Mol Biol Lett. 2011;16(4):515-38. doi:10.2478/s11658-011-0021-0.

7. Vidya Priyadarsini R, Senthil Murugan R, Nagini S. Aberrant activation of Wnt/beta-catenin signaling pathway contributes to the sequential progression of DMBA-induced HBP carcinomas. Oral Oncol. 2012;48(1):33-9. doi:10.1016/j.oraloncology.2011.08.008.

8. Nusse R. WNT targets. Repression and activation. Trends Genet. 1999;15(1)):1-3.

9. Castelo-Branco G, Wagner J, Rodriguez FJ, Kele J, Sousa K, Rawal N, et al. Differential regulation of midbrain dopaminergic neuron development by Wnt-1, Wnt-3a, and Wnt-5a. Proc Natl Acad Sci U S A. 2003;100(22):12747-52. doi:10.1073/pnas.1534900100.

10. Castelo-Branco G, Rawal N, Arenas E. GSK-3beta inhibition/beta-catenin stabilization in ventral midbrain precursors increases differentiation into dopamine neurons. J Cell Sci. 2004;117(Pt 24):5731-7.

11. De Ferrari GV, Chacon MA, Barria MI, Garrido JL, Godoy JA, Olivares G, et al. Activation of Wnt signaling rescues neurodegeneration and behavioral impairments induced by beta-amyloid fibrils. Mol Psychiatry. 2003;8(2):195-208. doi:10.1038/sj.mp.4001208.

12. Lin S, Cheng M, Dailey W, Drenser K, Chintala S. Norrin attenuates proteasemediated death of transformed retinal ganglion cells. Mol Vis. 2009;15:26-37.

13. Chong ZZ, Shang YC, Hou J, Maiese K. Wnt1 neuroprotection translates into improved neurological function during oxidant stress and cerebral ischemia through AKT1 and mitochondrial apoptotic pathways. Oxid Med Cell Longev. 2010;3(2):153-65. doi:10.4161/oxim.3.2.11758.

14. L'Episcopo F, Serapide MF, Tirolo C, Testa N, Caniglia S, Morale MC, et al. A Wnt1 regulated Frizzled-1/beta-Catenin signaling pathway as a candidate regulatory circuit controlling mesencephalic dopaminergic neuron-astrocyte crosstalk: Therapeutical relevance for neuron survival and neuroprotection. Mol Neurodegener. 2011;6:49. doi:10.1186/1750-1326-6-49.

15. Wei L, Sun C, Lei M, Li G, Yi L, Luo F, et al. Activation of Wnt/beta-catenin pathway by exogenous Wnt1 protects SH-SY5Y cells against 6-hydroxydopamine toxicity. J Mol Neurosci. 2013;49(1):105-15. doi:10.1007/s12031-012-9900-8. 
16. Luo F, Wei L, Sun C, Chen X, Wang T, Li Y, et al. HtrA2/Omi is involved in 6-OHDA-induced endoplasmic reticulum stress in SH-SY5Y cells. J Mol Neurosci. 2012;47(1):120-7. doi:10.1007/s12031-011-9694-0.

17. Dong J, Song N, Xie J, Jiang H. Ghrelin antagonized 1-methyl-4-phenylpyridinium (MPP(+))-induced apoptosis in MES23.5 cells. J Mol Neurosci. 2009;37(2):182-9. doi:10.1007/s12031-008-9162-7.

18. Yu S, Liu M, Gu X, Ding F. Neuroprotective effects of salidroside in the PC12 cell model exposed to hypoglycemia and serum limitation. Cell Mol Neurobiol. 2008;28(8):1067-78. doi:10.1007/s10571-008-9284-Z.

19. Zhang Z, Cao X, Xiong N, Wang H, Huang J, Sun S, et al. DNA polymerasebeta is required for 1-methyl-4-phenylpyridinium-induced apoptotic death in neurons. Apoptosis. 2010;15(1):105-15. doi:10.1007/s10495-009-0425-8.

20. Hwang CK, Chun HS. Isoliquiritigenin isolated from licorice Glycyrrhiza uralensis prevents 6-hydroxydopamine-induced apoptosis in dopaminergic neurons. Biosci Biotechnol Biochem. 2012;6(3):536-43.

21. Grimes CA, Jope RS. The multifaceted roles of glycogen synthase kinase 3beta in cellular signaling. Prog Neurobiol. 2001;65(4):391-426.

22. Sinha D, Wang Z, Ruchalski KL, Levine JS, Krishnan S, Lieberthal W. Lithium activates the Wnt and phosphatidylinositol 3-kinase Akt signaling pathways to promote cell survival in the absence of soluble survival factors. Am J Physiol Renal Physiol. 2005;288(4):F703-13. doi:10.1152/ajprenal.00189.2004.

23. Takahashi T, Deng Y, Maruyama W, Dostert P, Kawai M, Naoi M. Uptake of a neurotoxin-candidate, (R)-1,2-dimethyl-6,7-dihydroxy-1,2,3,4-tetrahydroisoquinoline into human dopaminergic neuroblastoma SH-SY5Y cells by dopamine transport system. J Neural Transm Gen Sect. 1994;98(2):107-18.

24. Blum D, Torch S, Nissou MF, Benabid AL, Verna JM. Extracellular toxicity of 6-hydroxydopamine on PC12 cells. Neurosci Lett. 2000;283(3):193-6.

25. Li Y, Luo F, Wei L, Liu Z, Xu P. Knockdown of glycogen synthase kinase 3 beta attenuates 6-hydroxydopamine-induced apoptosis in SH-SY5Y cells. Neurosci Lett. 2011;487(1):41-6. doi:10.1016/j.neulet.2010.09.070.

26. Soto-Otero R, Mendez-Alvarez E, Hermida-Ameijeiras A, Munoz-Patino AM, Labandeira-Garcia JL. Autoxidation and neurotoxicity of 6-hydroxydopamine in the presence of some antioxidants: potential implication in relation to the pathogenesis of Parkinson's disease. J Neurochem. 2000;74(4):1605-12.

27. Elkon H, Melamed E, Offen D. 6-Hydroxydopamine increases ubiquitinconjugates and protein degradation: implications for the pathogenesis of Parkinson's disease. Cell Mol Neurobiol. 2001;21(6):771-81.

28. Wodarz A, Nusse R. Mechanisms of Wnt signaling in development. Annu Rev Cell Dev Biol. 1998;14:59-88. doi:10.1146/annurev.cellbio.14.1.59.

29. Zhou T, Hu Y, Chen Y, Zhou KK, Zhang B, Gao G, et al. The pathogenic role of the canonical Wnt pathway in age-related macular degeneration. Invest Ophthalmol Vis Sci. 2010;51(9):4371-9. doi:10.1167/iovs.09-4278.

30. Wang KP, Bai Y, Wang J, Zhang JZ. Morphine protects SH-SY5Y human neuroblastoma cells against Dickkopf1-induced apoptosis. Mol Med Rep. 2015;11(2):1174-80. doi:10.3892/mmr.2014.2832.

31. Dun $Y$, Yang $Y$, Xiong $Z$, Feng $M$, Zhang $Y$, Wang $M$, et al. Induction of Dickkopf-1 contributes to the neurotoxicity of MPP+ in PC12 cells via inhibition of the canonical Wnt signaling pathway. Neuropharmacology. 2013;67:168-75. doi:10.1016/j.neuropharm.2012.10.031.

32. Chen G, Bower KA, Ma C, Fang S, Thiele CJ, Luo J. Glycogen synthase kinase 3beta (GSK3beta) mediates 6-hydroxydopamine-induced neuronal death. FASEB J. 2004;18(10):1162-4. doi:10.1096/fj.04-1551fje.

33. Yao G, Yang L, Hu Y, Liang J, Hou Y. Nonylphenol-induced thymocyte apoptosis involved caspase-3 activation and mitochondrial depolarization. Mol Immunol. 2006;43(7):915-26. doi:10.1016/j.molimm.2005.06.031.

34. Shin SY, Kim CG, Jho EH, Rho MS, Kim YS, Kim YH, et al. Hydrogen peroxide negatively modulates Wnt signaling through downregulation of betacatenin. Cancer Lett. 2004;212(2):225-31. doi:10.1016/j.canlet.2004.03.003.

35. Chong ZZ, Hou J, Shang YC, Wang S, Maiese K. EPO relies upon novel signaling of Wnt1 that requires Akt1, FoxO3a, GSK-3beta, and beta-catenin to foster vascular integrity during experimental diabetes. Curr Neurovasc Res. 2011;8(2):103-20.

36. Chong ZZ, Kang JQ, Maiese K. Erythropoietin is a novel vascular protectant through activation of Akt1 and mitochondrial modulation of cysteine proteases. Circulation. 2002;106(23):2973-9.

37. Rodriguez-Blanco J, Martin V, Herrera F, Garcia-Santos G, Antolin I, Rodriguez C. Intracellular signaling pathways involved in post-mitotic dopaminergic PC12 cell death induced by 6-hydroxydopamine. J Neurochem. 2008;107(1):127-40. doi:10.1111/j.1471-4159.2008.05588.x.
38. Johnson-Farley NN, Travkina T, Cowen DS. Cumulative activation of akt and consequent inhibition of glycogen synthase kinase-3 by brain-derived neurotrophic factor and insulin-like growth factor-1 in cultured hippocampal neurons. J Pharmacol Exp Ther. 2006;316(3):1062-9.

\section{Submit your next manuscript to BioMed Central and take full advantage of:}

- Convenient online submission

- Thorough peer review

- No space constraints or color figure charges

- Immediate publication on acceptance

- Inclusion in PubMed, CAS, Scopus and Google Scholar

- Research which is freely available for redistribution

Submit your manuscript at www.biomedcentral.com/submit 